\title{
Windfall Gains, Political Economy and Economic Development
}

\author{
Carl-Johan Dalgaard ${ }^{\mathrm{a}}$ and Ola Olsson ${ }^{\mathrm{b}, *}$ \\ a Department of Economics, University of Copenhagen, \\ Copenhagen, Denmark \\ ${ }^{b}$ Department of Economics, Göteborg University, Göteborg, \\ Sweden
}

Natural resource rents and foreign aid have the character of windfall gains that affect economic outcomes both directly and indirectly. Several studies have shown that the indirect effect typically works via institutions like corruption. In this article, we offer a theoretical framework for a joint analysis of how natural resources and aid potentially affect total output in society through rent-seeking activities. We survey the existing evidence on both direct and indirect effects of windfalls and provide some new empirical evidence of the association between aid/natural resources and institutions in a large cross-section of countries. Our results suggest that whereas more aid means less corruption, natural resource rents is positively correlated with corruption, although both relationships are non-linear.

JEL classification: $017,043, P 16$

\section{Introduction}

In order to understand long-run economic performance, it is inevitable to address the interaction between institutions, politics and markets. Institutions form the rules of the game within which both politics and markets operate and ultimately determine economic performance (North, 1990; Acemoglu et al., 2005). Recent research has strongly indicated that institutional and political *Corresponding author: Ola Olsson, Department of Economics, Göteborg University, Göteborg, Sweden. E-mail: ola.olsson@economics.gu.se

(C) The author 2008. Published by Oxford University Press on behalf of the Centre for the Study of African Economies. All rights reserved. For permissions, please email: journals.permissions@oxfordjournals.org 
failure is among the most likely explanations to persistent underdevelopment. The deeper question is of course what causes institutional failure. In this paper, we focus on two types of shocks to the politico-institutional nexus described above; natural resource rents and foreign aid.

There is by now an extensive literature on the macroeconomic effects of natural resource rents and foreign aid. Several authors have noted that although aid and resource rents have some important differences, they share the general character of 'windfall gains' that disrupt political and economic incentives (Acemoglu et al., 2004). In Figure 1, we illustrate the potential effects of the two types of income streams on society at large.

A predominantly empirical line of research has focused on the 'reduced-form' relationship between resource rents and aid on the one hand, and economic performance on the other (the long arrows in Figure 1). The 'resource curse'-literature received its major impetus by the findings of Sachs and Warner $(1997,2001)$ who showed that countries with a large share of primary sector exports to GDP tended to have lower growth rates than countries with smaller primary sector exports. Based on their data, Sachs and Warner identified Dutch disease as the most likely explanation to this patterns, i.e., that the inflow of resource rents led to a

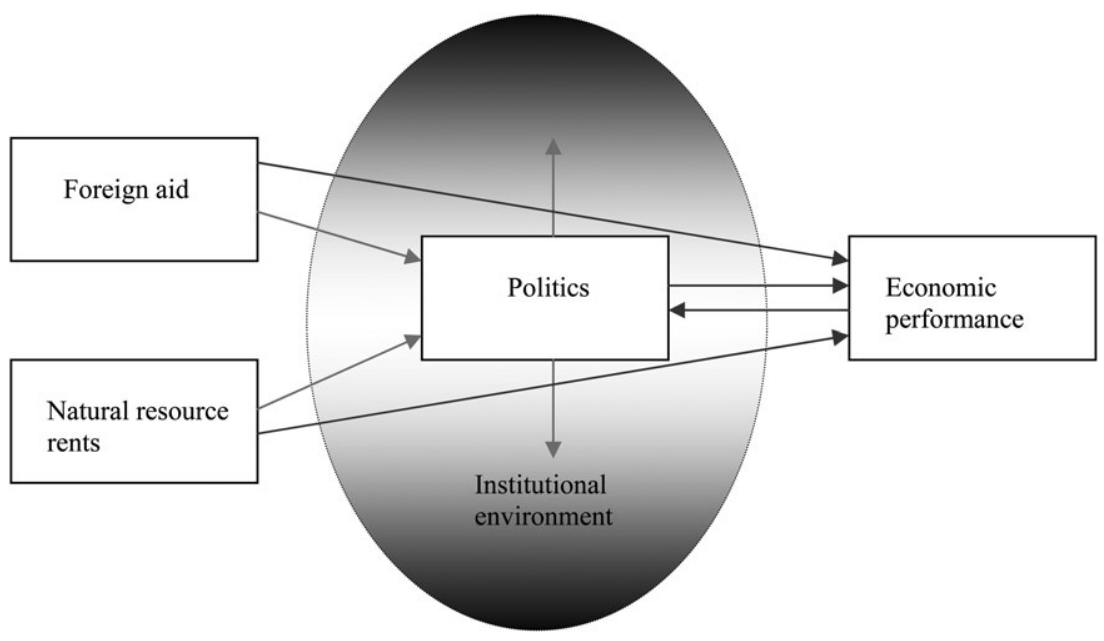

Figure 1: Direct and Indirect Causal Effects of Foreign Aid and Natural Resource Rents. 
crowding-out of the manufacturing sector (Corden and Neary, 1982). Later works, for instance Sala-i-Martin and Subramanian (2003), have suggested that the primary link between resource rents and growth rather runs through institutions and politics.

Similarly, the potentially beneficial effects of foreign aid have been debated for decades in the academic literature. From a theoretical perspective the expectation would be that aid, mainly by stimulating capital accumulation, should be able to increase labour productivity in recipient nations. At the same time, however, aid dependent nations could easily end up with Dutch Disease symptoms, leaving the net impact ambiguous. ${ }^{1}$ As a result, a large empirical literature has over the years examined the impact of aid on growth. The early empirical literature, surveyed in Hansen and Tarp (2000), seemed to indicate that aid was by-and-large ineffective in raising growth. More recent empirical work from the late 1990s and onwards have modified this conclusion somewhat. Although aid often is found to be able to increase long-run labour productivity, the impact is not uniformly positive across recipients. ${ }^{2}$ The source of this apparent variation in impact from aid is still not fully understood. It is doubtful that more 'reduced-form' regressions of aid on growth will lead to a resolution to this issue.

Accordingly, in this paper, we will attempt to go beyond the reduced-form results and concentrate on the mechanisms through which natural resource rents and foreign aid affect politics and institutions in developing countries. We start by outlining a simple political economy model that forms the theoretical background to our subsequent analysis. The model shows that windfalls basically might have two major influences; first to increase harmful rent-seeking efforts and thereby crowd out productive activities, but secondly also to increase overall labour productivity. We then provide a critical review of the existing research in both the 'reduced-form' literature and within the more recent tradition that focuses on windfalls and politics. We further present some empirical results of our own suggesting that the impact of resource rents and foreign aid on institutional quality indeed appears to be nonlinear, as our own model suggest.

${ }^{1}$ Indeed, it is not uncommon for aid and natural resource flows to be treated as equivalent income sources in theoretical work on this topic. See e.g. the theoretical analysis of the Dutch Disease phenomenon by Torvik (2001).

2 See Clemens et al. (2004) for a survey. 
To our knowledge, we provide the first survey of the the effects of windfall gains in the literature. We also believe that we contribute to the literature by offering a joint theoretical and empirical framework for analysing the effects of foreign aid and natural resource rents on institutions. Such a line of inquiry appears to be particularly relevant for African countries where windfalls in general are large and institutions weak. The results presented in the last section regarding the non-linear association between windfalls and corruption suggest that further research in this area is needed, as existing empirical work on the topic generally has assumed the impact of windfalls on corruption is linear.

The outline of the paper is as follows: in section 2, we discuss the differences and similarites between natural resource rents and foreign aid from a number of perspectives. In section 3, we present the theoretical model where it is analysed how windfalls affect rent seeking and labour productivity. In sections 4 and 5, we review the literature on the reduced-form impact of windfalls on growth, as well as the indirect effect working through institutional quality. Our new empirical evidence is presented in section 6 , and section 7 concludes the paper.

\section{Aid and Resource Rents as Windfalls}

The basic premise of this article is that aid and natural resource rents both have the character of windfall gains that poor countries can benefit from without much effort. More precisely, the key element of windfall gains is in our view a disproportional revenue-to-cost ratio. We believe that this characterisation is reasonable and puts a finger on a central difference between revenue in this form and revenues from standard production of goods and services. This distinction is indeed also a key notion in many papers in the political economy tradition (Svensson, 2000; Acemoglu et al., 2004). ${ }^{3}$

However, our characterisation of windfalls calls for a number of clarifications. We believe that aid and resource rents have important distinguishing features that need to be addressed. In this section, we

${ }^{3}$ Some authors associate windfall gains with an unexpected increase in the level of rents, for instance from a temporary terms of trade shock (Tornell and Lane, 1998). Instances of such shocks include the rise in coffee prices 1975-79 and in oil during 1979-82. 
will discuss those features along the following dimensions: endogeniety to levels of development, external influence, incentives, appropriability, fixed costs, externalities and the degree of volatility.

The most fundamental difference between the two windfall gains lie in how they are distributed across the globe. Foreign aid is almost exclusively granted to countries with low GDP per capita whereas reserves of valuable natural resources are more randomly allocated over the planet. The capability of generating rents from these reserves could to some extent be endogenous to levels of development (Stijns, 2001), but to a much smaller degree than aid. Moreover, no political decisions can change the fact that Iran, Iraq and Nigeria are heavily endowed with oil, whereas financial support to countries like these can be easily reverted. This issue is particularly important when it comes to identifying the impact of windfalls on labour productivity; the endogeniety problem is likely to be more severe in the case of aid. But the two windfalls also differ in other respects.

Another important difference consists of whether the use of windfalls is subject to external influence. This is obviously the case for aid; foreign donors often have strong ideas about how the donations are to be spent, and moreover what economic policies that should be undertaken in the country in general. Although Western donors often have very specific pet objectives like promoting French culture, fighting terrorism or gender equality, they all typically prefer democratic, accountable, and fiscally responsible governments that are committed to poverty alleviation, education and health care rather than to military spending and state regulation of markets. The external influence associated with aid is therefore necessarily large, and may also provide some incentives for governments to perform 'well'. ${ }^{4}$ Natural resource rents are not associated with external influence to the same extent. Large, state-owned monopolies in the mineral sector are often a significant

4 Aid allocation studies, for example, does suggest aid inflows are affected by whether countries are democratic or not (Alesina and Dollar, 2000). This does not mean that all kinds of 'good behavior' is rewarded. For example, there is little evidence that less corrupt governments receive less aid (e.g., Neumeyer, 2003). In addition, since low income is a strong predictor of aid allocations this could provide an incentive on the part of the recipient to pursue policies which do no raise income so as to ensure a continual stream of aid. This scenario leaves the donor with a 'Samaritan's dilemma' (Buchanan, 1975). Accordingly, external influence could also induce 'bad' policy behaviour inadvertently. For recent work on how to avoid such 'capture', see e.g., Coate (1995). 
source of resource revenue for African governments and provide means that can be used in a discretionary manner. Nonetheless, foreign firms are sometimes heavily involved in the extraction process and exert a large influence in several countries. Examples include the joint venture between the state of Botswana and the private firm De Beers (Debswana) in the diamond sector and British-owned Shell's engagements in Nigeria's oil business. However, revenue from state-controlled resource rents typically continue flowing even if the president turns autocratic and starts to expropriate private property.

The extent of foreign involvement associated with the two forms of windfalls influences attempts to empirically identify their impact on labour productivity, or other outcome measures such as corruption, for two reasons. First, foreign aid can be seen as a 'package' involving resource flows and terms of (policy) conditionality, the impact of which is hard to separate from one another. This issue is less acute when it comes to natural resource rents.

The second reason why foreign influence might matter relates to the degree to which the funds can be appropriated by a government. Appropriability refers to the ease with which aid and resource rents can be captured by rent seekers and predators. If aid is highly targeted on a micro level and without government involvement, it is not easily appropriated either by the elites around the government or by other parties. Unconditional budget support is of course a more appropriable form of aid. As described more thoroughly in Boschini et al. (2003) and Olsson (2006), many natural resources are highly appropriable, in particular precious minerals like diamonds and gold.

Aid and resources also differ in terms of the fixed costs of operation. Aid flows are associated with certain administrative costs but these are arguably relatively minor. The creation of an efficient resource sector might however induce substantial fixed costs. Oil drilling and modern kimberlite diamond mining require both large amounts of capital and expertise which might constitute serious hurdles for poor African countries. The revenue-to-costs ratio in certain mature mineral sectors like iron ore is further quite low, possibly too low to be characterised as an activity generating windgall gains.

Finally, there are two other differences worth pointing out. The first relates to the extent that externalities are involved in the 
context of the flows, and the second relates to the volatility of the rents.

The inflow of aid and resource rents to some segment of society could have externalities on other segments. For instance, an aidsupported construction of a dam might not just bring more electricity but also environmental hazards to the people in the river valleys. Likewise, mining and oil production are large-scale operations with important backward and forward linkages to industry but also often with serious environmental consequences. ${ }^{5}$ Modern aid has however increasingly turned away from financing large-scale industrial projects.

A common theme in the literature is further the great volatility in natural resource prices and hence in revenues. Some writers even view windfall gains as being an unexpected increase in resource revenue rather than a high level of the same (Tornell and Lane, 1998). Manzano and Rigobon (2001) and others document how commodity prices experienced a boom in the mid 1970s followed by a dramatic general decline in the 1980s. The most apparent example of commodity price volatility is naturally crude oil. During the two oil shocks, revenues soared for the oil-producing countries in a previously unheard of manner. Aid inflows, on the other hand, are likely to have a smaller intertemporal variance and a less stochastic nature.

\section{A Theoretical Framework}

In order to analyse the effects of natural resource rents and aid on politics, let us consider a variant of the well-known contest success function, originally proposed by Tullock (1974) to describe rent seeking contests, but nowadays used in numerous other applications. ${ }^{6}$ Given the purpose at hand, we have tried to keep the model as small as possible, which has forced us to disregard

${ }^{5}$ A common claim in the literature is that the backward and forward linkages in the natural resource sectors are not as extensive as those in manufacturing, which is one reason why manufacturing is regarded as a more 'useful' type of production in the long run (Matsuyama, 1992).

6 See for instance Grossman (1991) for an equilibrium model of insurrections, Grossman and Kim (1995) for a model of the security of claims to property, and Olsson and Congdon Fors (2004) and Olsson (2007) where a rebel group and an autocratic ruler fight over a resource initially controlled by the ruler. An overview is provided by Neary (1997). 
several important aspects such as dynamic considerations, multiple interest groups, elections, taxation and government spending patterns. ${ }^{7}$

Let us imagine a developing country with two types of agents or groups; a more or less autocratic government and their supporters on the one hand, and the rest of the citizenry on the other. Somehow both groups have solved the problems of collective action and are able to act as one agent. The citizens have a labour endowment of $n_{c}$ which they might split between production time $l_{c}$ and unproductive rent seeking or predation $r$ with the usual restriction that $l_{c}+r=n_{c}$. Total ordinary production is linear in labour $y_{c}=A l_{c}$ where $A$ is a common productivity parameter reflecting all kinds of non-rivalrous productivity-enhancing factors such as a favourable geography, a well-developed infrastructure or a good access to technology.

The country benefits from a rent flow $F$ which is distinct from ordinary production. In our model, this is meant to describe resource rents or foreign aid. We assume that only a fraction $\gamma$ of this rent flow is appropriable and is the object of the citizens' potential predation or rent-seeking efforts. ${ }^{8}$ The remaining share $1-\gamma$ is not appropriable. The basic idea behind this assumption is that $\gamma$ reflects the degree to which the rent flows are under the government's discretion. If, for instance, all revenue from natural resources flows into the government budget and if aid is unconditional, $\gamma$ is high. If, on the other hand, resource flows are automatically funded or tied up in specific projects and if aid is strongly conditional, $\gamma$ will be low.

The share of the appropriable rents $\gamma F$ that the people manage to conquer is $p \in[0,1]$ defined in the simplest form of contest success function as:

$$
p=\frac{r}{r+\alpha d}=\frac{1}{1+\frac{\alpha d}{r}}
$$

where $d$ is the elite's defence efforts and $\alpha>0$ reflects the general capacity of the government to uphold the rule of law and the protection of property. $\alpha$ might thus be thought of as an indicator of

${ }_{8}^{7}$ For a richer model capturing some of these effects, see for instance Olsson (2007).

${ }^{8}$ In this simple framework, rent seeking and predation are just regarded as different levels of intensity of the same basic activity. 
institutional strength. The normal case should of course be that $\alpha>$ 1 so that the marginal effectiveness of $d$ is greater than that of $r$.

The government and their loyal supporters (the elite) have a labour endowment that can be used either in ordinary production or for defending the appropriable rents that they control. Their total labour endowment is $n_{e}=l_{e}+d$ where $l_{e}$ is labour in peaceful production, producing a level of output $y_{e}=A l_{e}$.

The utility function of citizens who stand in opposition to the current elite is:

$$
U_{c}=y_{c}+p \gamma F=A\left(n_{c}-r\right)+\frac{\gamma F}{1+\frac{\alpha d}{r}},
$$

whereas the utility of the elite that is in government is

$$
U_{e}=y_{e}+(1-p) \gamma F=A\left(n_{e}-d\right)+\frac{\gamma F}{1+\frac{r}{\alpha d}} .
$$

The total level of income for the country is:

$$
\begin{aligned}
& Y=y_{c}+p \gamma F+y_{e}+(1-p) \gamma F+(1-\gamma) F \\
& =A\left(n_{c}+n_{e}-d-r\right)+F .
\end{aligned}
$$

From a social point of view, welfare is of course maximised when predation and defence efforts are set to be $d=r=0$. The struggle over resources $F$ is a zero-sum game and only entails a waste of productive efforts. ${ }^{9}$ A key insight from the model is however that zero rent-seeking efforts are not rational in a decentralised scenario where each type of agent makes their decisions on their own.

To see why, let us consider a situation when agents make their strategic choices of labour effort simultaneously, taking into account the known reaction of the other agent. ${ }^{10}$ By deriving the first-order conditions and solving in the usual way, we obtain the best-response functions:

$$
r^{b}(d)=\sqrt{\frac{\alpha d \gamma F}{A}}-\alpha d \geq 0
$$

9 In some models, for instance in Grossman and Kim (1995), the struggle is not just wasteful but also destroys $F$ to a certain extent.

${ }^{10}$ In Olsson and Congdon Fors (2004) and Olsson (2006), a sequential predator-prey game is assumed instead where ruling elite makes the first move. 
and

$$
d^{b}(r)=\sqrt{\frac{r \gamma F}{\alpha A}}-\frac{r}{\alpha} \geq 0
$$

Upon substitutions, it turns out that the unique Cournot-Nash equilibrium levels of predatory and defensive efforts are:

$$
d^{*}=r^{*}=\frac{\alpha \gamma F}{A(1+\alpha)^{2}} .
$$

In other words, the total level of effort devoted to rent seeking or corruption increases with the size of appropriable rents $\gamma F$, decreases with the marginal productivity of labour in production $A$, and decreases (increases) with relative government strength $\alpha$ if $\alpha>1(\alpha<1) .{ }^{11}$ In the normal case $(\alpha \geq 1)$ an increase in $\alpha$ will deter the citizens from predating and hence less defence efforts will be necessary. Of particular relevance is further the 'rents-productivity'-ratio $F / A$ which might be thought of as reflecting the opportunity cost of normal production. The model implies that countries with large rents coupled with a low labour productivity (and hence a large opportunity cost of peaceful production) are prone to intense appropriative conflict. This situation is of course what characterises many African countries. However, a crucial role is also played by $\gamma$. If rents are not readily appropriable so that $\gamma$ is small, $d^{*}$ and $r^{*}$ will be low. ${ }^{12}$

The equilibrium level of total income is easily found to be:

$$
Y^{*}=A\left(n_{c}+n_{e}-\frac{2 \alpha \gamma F}{A(1+\alpha)^{2}}\right)+F .
$$

It is clear from this expression that rents $F$ have a direct positive effect on aggregate income as well as an indirect crowding-out

11 The result regarding $\alpha$ stems from the fact that the derivative of the expression in equation (6) is equal to $\gamma F(1-\alpha) / A(1+\alpha)^{3}$, the sign of which clearly depends on the level of $\alpha$ above or below unity. By l'Hopital's rule, it can be shown that $\lim _{\alpha \rightarrow 0}\left(r^{*}+\mathrm{d}^{*}\right)=\lim _{\alpha \rightarrow 0}(\gamma F / A(1+\alpha))=0$.

12 The result in (6) is well in line with the three conditions listed by Aidt (2003) for corruption to exist: discretionary power for public officials $(\gamma)$, economic rents $(F)$, and weak institutions $(\alpha)$. 
effect. ${ }^{13}$ Comparative statics shows that the positive effect dominates, implying that income increases by larger rents:

$$
\frac{\partial Y^{*}}{\partial F}=\frac{-2 \alpha \gamma}{(1+\alpha)^{2}}+1=\frac{2 \alpha(1-\gamma)+1+\alpha^{2}}{(1+\alpha)^{2}}>0 .
$$

However, the rent inflow also causes a shortfall in production at a magnitude of $(-2 \alpha \gamma) /\left((1+\alpha)^{2}\right)$. This loss of production will decrease with the strength of the rule of law $\alpha$ and increase with the fraction of appropriable rents, $\gamma$. Obviously, if $\gamma=0$ or if $\alpha \rightarrow$ $\infty$, there will be no crowding-out at all. The prevalence of a negative impact of windfalls thus depends crucially on these two institutional factors.

The assumption that aid and natural resources only provide a flow of money that is isolated from the rest of the economy is however somewhat simplistic. One might for instance easily imagine that natural resource production could create linkages to other types of production so that labour productivity is enhanced in the rest of the economy. Likewise, even if aid exclusively takes the form of budget support to the government, it might contribute to stabilising the general macroeconomic situation, which in turn might influence labour productivity positively depending on the country's absorption capacity. ${ }^{14}$

Let us therefore consider an extension of the framework above, where rents have a positive external effect on productivity so that $A(F)$ with the properties $A^{\prime}(F)>0, A^{\prime \prime}(F)<0$ and $A^{\prime}(0)=\infty$. In this case, there are three effects on total national income; a positive direct revenue effect, a negative indirect crowding-out effect, and thirdly a positive indirect spillover effect. ${ }^{15}$ If we look at the aggregate effect on total production, the presence of the two indirect effects imply a concave function with an indeterminate sign of the

13 This type of crowding-out is of course distinct from the standard form of Dutch disease where an inflow of resource rents lead to an appreciation of the currency and a staggering manufacturing sector.

14 That aid possibly could buy 'tranquility' was suggested early on by Chenery and Strout (1966). As pointed out by our discussant, aid might also cause governments to grow, which might have both positive and negative consequences.

15 See also Hodler (2006) for a model which captures competition for public funds (indirectly aid), and where aid simultaneously may impact on productivity by increasing productive government investments. 
first derivative:

$$
\frac{\partial\left(y_{c}^{*}+y_{e}^{*}\right)}{\partial F}=A^{\prime}(F)\left(n_{c}+n_{e}\right)-\frac{2 \alpha \gamma}{(1+\alpha)^{2}} .
$$

Obviously, at low levels of $F$, the sign of the derivative will be positive and then reach a maximum defined at the level of $F$ where

$$
A^{\prime}(F)=\frac{2 \alpha \gamma}{\left(n_{r}+n_{e}\right)(1+\alpha)^{2}}
$$

applies.

The interesting aspect of this result is that it is capable of specifying under what conditions windfall gains will have an overall harmful effect on ordinary production. Figure 2 shows the relationship between total production and the level of rents under different institutional regimes, i.e., when we allow $\alpha$ to range from very low (unity) to very high.

As shown in the figure, the negative impact of rents occurs at levels of $F$ to the right of the maximum. A strong rule of law

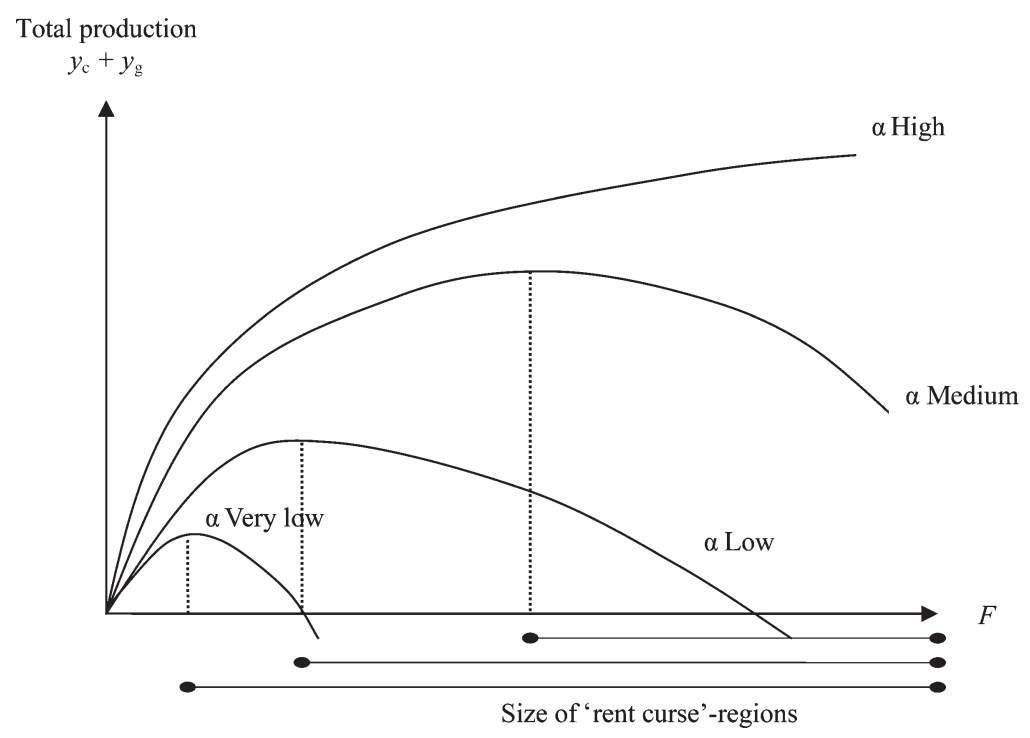

Figure 2: The Relationship between Total Production and Rents under Different Institutional Regimes $(\alpha \geq 1)$. 
implies that the maximum is not in the feasible range of values for $F$. There will therefore be no aid or resource curse at all since rents will not cause any crowding-out. At lower levels of institutional strength, the maxima are within the feasible range and the 'rent curse'-regions might be large. If economies have such moderate levels of $F$, further inflows of rents will cause a decline in total production. As we shall see, this insight might explain some results from the empirical literature that aid and resource rents are not harmful in countries like Botswana where rule of law and strong property rights prevail. The expression in (9) further implies that regardless of the level of $\alpha$, a $\gamma$ close to zero will also lead to an escape from the negative effects. Appropriability is thus a central concern. We will return to both of these arguments below.

\section{Windfalls and Labour Productivity}

\subsection{Natural Resource Rents}

At least since the work of Sachs and Warner (1997), economists have recognised that there appears to be a 'natural resource curse' in the sense that countries with a large share of primary exports to GDP tend to have had lower growth rates since 1960.16 Sachs and Warner's basic empirical setting follows the logic of 'Barro-type' growth regressions. They estimate the equation:

$$
\left(\log y_{i, t}-\log y_{i, t-\tau}\right) / \tau=\beta_{0}+\beta_{1} \log y_{i, t-\tau}+\beta_{2} r_{i, t-\tau}+X_{i, t-\tau}^{\prime} \eta+u_{i, t},
$$

where $y_{i, t}$ is GDP per capita at time $t$ for country $i,\left(\beta_{0}, \beta_{1}, \beta_{2}, \eta\right)$ are parameters to be estimated, $r_{i, t}$ is some indicator of natural resource abundance, $X_{i, t}^{\prime}$ is a vector of control variables and $u_{i, t}$ is a normally distributed error term. The time period considered for the crosssection analysis is 1970-90. Sachs and Warner's main proxy for $r_{i, t}$ is the share of primary sector exports as a share of GDP in initial year 1970 (SXP). They also use three more measures; the share of mineral production to GDP, the share of primary exports to total exports, and the log of land area per person.

The main focus of interest is of course on $\beta_{2}$. It turns out that this parameter is negative and strongly significant in all specifications, regardless of the variable for natural resource abundance used.

16 See also Papyrakis and Gerlagh (2007) for a similar result for US states. 
The size of the estimates imply that a unit standard deviation increase in SXP is associated with a fall in growth rates that ranges from -1.51 percentage points to -0.62 , depending on the specification. The authors then address the issue of whether $r_{i, t}$ could potentially also have an effect through some of the variables in $X_{i, t}^{\prime}$, for instance through institutional quality. Such an indirect effect is found to exist in the data but is relatively small. Based on their findings, Sachs and Warner (1997) conclude that the direct effect of natural resource abundance on growth dominates, which in their view lends support to a Dutch disease explanation where natural resource revenue crowds out labour from the manufacturing sector and hence hampers long-run growth. ${ }^{17}$

Even though Sachs and Warner's original NBER-version has remained unpublished, it initiated a new line of research. In Sachs and Warner (2001), the authors reacted to a common line of criticism that the results might be spurious due to omitted variable bias. Specifically, suppose there exists a growth determinant, $z$, which is omitted from the regression analysis. In the interest of clarity, one could think of $z$ as 'geography'. Imagine further that geography is uncorrelated (to a first approximation) with resource endowments, i.e., the numerator in $r$. Accordingly, countries situated in beneficial geographic environments will tend to be economically successful, which would imply relatively high levels of GDP. Consequently, $r$ (resources as a fraction of GDP) will tend to be low in (rapidly growing) prosperous places, and high in (poorer) economies experiencing modest growth. ${ }^{18}$ The authors met this criticism by arguing that the most likely omitted factor in their previous work was geography and therefore included a number of new geography controls such as percentage of coastal population and a malaria index. They also tried controlling for lagged growth rates to control for (time invariant) omitted factors more generally. In either case, SXP remained negative and significant.

${ }^{17}$ In a careful study of direct and indirect effects of resource abundance, Papyrakis and Gerlagh (2004) show that the indirect effects tend to dominate and that the most important transmission channel appears to be that the resource abundance hampers physical investment. See also Gylfason (2001) for results indicating that education could be an important intermediate variable.

18 In general any variable $z$ which matters for growth while being correlated with resources as a fraction of GDP (for whatever reason) would bias the OLS estimate of resources on growth, if omitted. Notice, however, that the direction of the bias implied by this argument is unknown. 
A related type of objection was raised by Manzano and Rigobon (2001) who pointed at the obvious fact that natural resource production is an integral part of both $y_{i, t}$ and SXP, which should affect the results. Their solution was to use primary exports as a share of GNP instead of GDP. This did not change the standard result in a cross-section of countries, but the measure became insignificant when the authors used a panel instead. Manzano and Rigobon's main argument was further that the primary reason for the 'curse' was that resource abundant countries in the 1970s used primary sector exports as collateral for extensive loans. When commodity prices fell drastically in the 1980s, these countries were left with a substantial debt overhang that had a strong negative effect on growth.

Stijns (2001) further makes the point that natural resource exploitation probably to some extent is endogenous to the level of economic development. Technologically backward countries simply are not able to exploit their natural resource reserves in the way that, for instance, Canada can. Furthermore, Stijns argues that reserves rather than production or exports of natural resources should be used in assessments of resource abundance. When using reserves of oil, minerals, gas and coal instead of SXP, there is no relationship left between natural resource abundance and growth.

Several works in the resource curse tradition have argued that the practice of lumping together for instance wheat and iron production with oil and diamonds in a measure like SXP is not ideal. Historical evidence seems to support that the latter two types of resources have had much more serious adverse effects on economic development than crops or iron ore. Boschini et al. (2003) and Olsson (2007) claim that the 'technical appropriability' of resources is central, i.e., the extent to which resources are suitable for becoming prizes in rent seeking or more violent types of conflict. ${ }^{19}$ Boschini et al. (2003) therefore use the production of gold, silver and diamonds as an indicator of the most extremely appropriable resources whereas Olsson (2007) only uses measures of diamond abundance.

Mehlum et al. (2006) as well as Boschini et al. (2003) and Olsson (2007) further show that the negative association between growth and natural resources is non-monotonic and typically is conditional upon the strength of institutions like property rights and the rule of

19 This aspect is captured by the parameter $\gamma$ in our model above. 
law (the empirical equivalents of $\alpha$ in our model). In the basic equation above, Mehlum et al. and the other two works add a measure of institutions $I_{i, t-\tau}$ (from Knack and Keefer (1995) ranging between 0 and 1 where stronger institutions have a higher score) with an associated coefficient $\beta_{3}$ as well as an interaction term $r_{i, t-\tau}{ }^{*} I_{i, t-\tau}$ with a coefficient $\beta_{4}$. All three works show that, as before, $\beta_{2}$ is negative whereas both $\beta_{3}$ and $\beta_{4}$ are positive. The marginal impact on growth of a change in the natural resource measure is thus $\beta_{2}+\beta_{4}{ }^{*} I_{i, t-\tau}$. The 'curse' is therefore mainly in place for countries with a low level of institutional quality. Mehlum et al.'s results imply that only 15 out of 87 countries in their sample have a level of institutions that allow them to escape the curse altogether (more precisely, they have an institutional quality of $I_{i, t-\tau}>-\beta_{2} / \beta_{4}$ $\approx 0.93$ ). This group includes the resource abundant countries United States, Canada, Norway, and Australia. ${ }^{20}$

In summary, although significant progress has been made in this largely 'reduced-form' empirical literature about how resource abundance and institutions interact to affect growth, most of the regressions referred to above have less to offer for a deeper understanding of the exact causal chains between natural resources, institutions, and development. These links will be discussed more thoroughly below.

\subsection{Foreign Aid}

The empirical literature on the growth impact of foreign aid is by now rather large. ${ }^{21}$ The conventional approach consists of examining the reduced form impact of aid, by way of growth regressions, using panel data. Accordingly, the typical analysis would have a regression model of the following sort at its base (where subscript $i$ refers to individual countries):

$$
\begin{aligned}
\left(\log y_{i, t}-\log y_{i, t-\tau}\right) / \tau= & \beta_{0}+\beta_{1} \log y_{i, t-\tau}+\beta_{2} a_{i, t-\tau}+\beta_{3} a_{i, t-\tau} \cdot Z \\
& +X_{i, t-\tau}^{\prime} \eta+u_{i, t},
\end{aligned}
$$

${ }^{20}$ When Boschini et al. (2003) use their measure 'Midas Production' (covering gold, silver, and diamond production) instead of SXP in an otherwise identical setup as in Mehlum et al. (2006), they find that even some countries with a level of institutional quality below the mean $\left.I_{i, t-\tau}<0.57\right)$ will escape the curse.

21 Recent contributions are surveyed in Clemens et al. (2004). The early literature is discussed in Hansen and Tarp (2000). 
where $y_{i, t}$ is GDP per capita at time $t,\left(\beta_{0}, \beta_{1}, \beta_{2}, \beta_{3}, \eta\right)$ are parameters to be estimated, $a_{i, t-\tau}$ is aid inflows as a fraction of GDP (on average between $t-\tau$ and $t$ ), $X_{i, t}^{\prime}$ is a vector of (mostly timevarying) controls, $Z$ is an 'interaction' variable and $u_{i, t}$ is a noise term which often is allowed to have both a time-varying and a country specific component. The interaction variable is added so as to test whether aid has the same impact on growth across recipients. As it turns out, aid is never found to have a uniform impact on labour productivity across countries; $\beta_{3}$ is always found to be significant. Debate continues to persist, however, about what ' $Z$ ' is. ${ }^{22}$

The most widely disseminated idea, due to Burnside and Dollar (2000), is that aid only stimulates economic growth if accompanied by sufficiently sound macroeconomic policies; e.g., low inflation and budget balance. This hypothesis can be tested by using an appropriately defined policy index in place of $Z$ in the equation above. If a larger value for the policy index means 'bad' policy, the prior would then be that $\beta_{2}>0$ but $\beta_{3}<0$, implying an over-all positive impact of aid on growth only if $Z<-\beta_{2} / \beta_{3}$. While Burnside and Dollar (2000) initially found support for this idea, later research has found it to be fragile (Dalgaard and Hansen, 2001; Easterly et al., 2004; Roodman, 2004 and others). As a result, a number of alternative hypothesis about ' $Z$ ' has since then been put forth. ${ }^{23}$

A recent careful study by Roodman (2004) re-examines the robustness of various candidates for ' $Z$ '. Specifically Roodman vary the specification, the underlying data (aid concept, definition of 'policy' etc), the data coverage, the periodisation (4 year average, 8 year averages etc) and deletes outliers. In the end Roodman concludes that the most robust finding in the recent literature on aid's impact on growth is 'the climate interaction', i.e., where $Z$ equals the fraction of land area in the tropics (Dalgaard et al., 2004). The regularity is that aid has been more effective in stimulating labour productivity in countries with only a modest fraction of its territory within the geographical tropics. There are several possible theoretical explanations for this fact. For present purposes we shall spell out two possibilities, of which one will be pursued in the remaining.

22 Some even doubt there is an effect of aid at all. A recent critique of the existing panel-data-based literature is found in Rajan and Subramanian (2005).

3 See Clemens et al. (2004) for a summary. 
A recent literature, pioneered by Galor and Weil (2000), provides an intriguing account of how countries emerge from a Malthusian equilibrium, where positive income shocks induce population growth, and venture onto a path of sustained growth where rising income is associated with declining fertility. ${ }^{24}$ The two regimes are divided by the demographic transition, which countries in tropical Sub-Saharan Africa only fairly recently have undergone, or are in the middle of (Reher, 2004). An aid transfer to a country in the Malthusian regime will lead to rising population growth, and a lowering of average labour productivity. ${ }^{25}$ In contrast, if the economy in question has transited from the Malthusian state of stagnation, i.e., have undergone the demographic transition, aid transfers may facilitate human capital accumulation to the benefit of growth. Hence, the first possible interpretation is that the tropics variable divides countries into groups according to whether they are in one or the other regime.

A second possible interpretation, however, is that the climate variable acts a stand-in for institutions. ${ }^{26}$ There is by now considerable evidence which suggest that climate-related circumstances mattered a great deal for the emergence of well functioning institutions. ${ }^{27}$ For the less developed regions of the world the most prominent work is that of Acemoglu et al. (2001) which suggest high mortality rates among stationed soldiers (a proxy for settler mortality) mattered for the colonisation strategy invoked by Western powers. Institutions conductive to private enterprise was only put in the place where Europeans chose to settle down; areas where mortality rates were fairly low. Since institutional infrastructure, according to the theory, is highly persistent, 'bad' institutions in the past will matter for outcomes today. As Figure 3 shows, there is a reasonably high correlation between fraction of land area in the tropics and $(\log )$ settler mortality rates (without being overly impressive, the correlation is 0.4 and significant).

${ }^{24}$ See Galor (2006) for a survey of the literature.

25 Azarnert (2004) demonstrates that aid flows to Africa has indeed been associated with increasing fertility.

26 This possibility is suggested in Dalgaard et al. (2004).

27 The work of Diamond (1997) is particularly noteworthy. Diamond argues that climatic circumstances in large part account for the emergence of specialists and the basic elements of the organised state, by allowing for agriculture and high population densities. See also Sokoloff and Engerman (2000). 


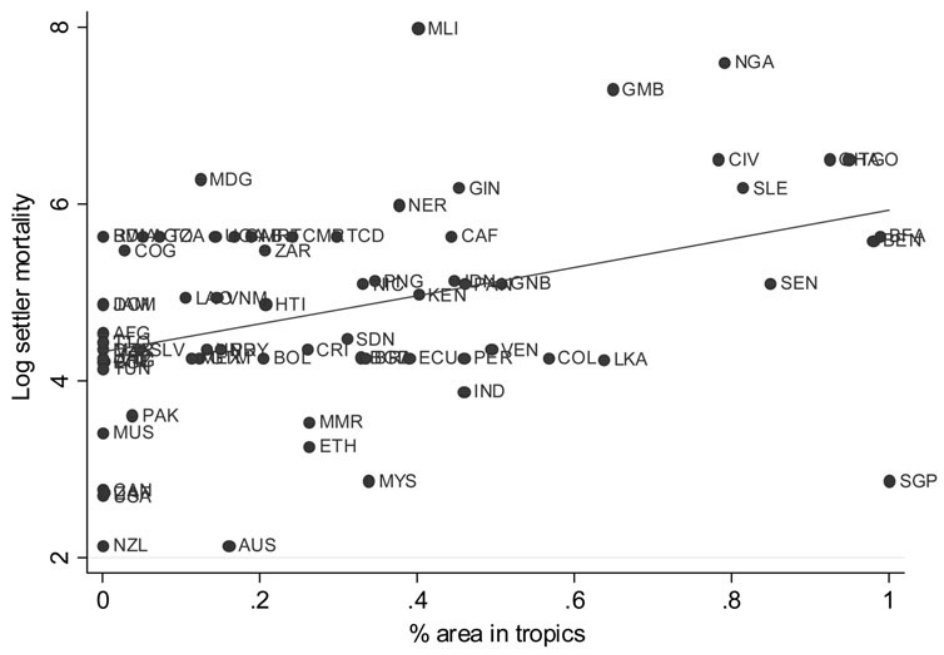

Figure 3: Correlation between Settler Mortality and Percentage of Area in the Tropics.

As a result, one may hypothesise that the climate variable simply is picking up exogenous determinants of 'institutions'. This would be consistent with the simple model developed above; the tropics variable is picking up the influence for ' $\alpha$ '. Moreover, this interpretation is potentially attractive in that it could align a number of different 'interaction effects' detected in the literature.

The so-called 'diminishing returns' hypothesis, which is usually associated with the work of Hansen and Tarp (2001), would be a case in point. ${ }^{28}$ Hansen and Tarp put $Z=$ aid, and proceed to find that $\beta_{2}>0$ whereas $\beta_{3}<0$. Hence, it seems that moderate inflows of aid increases growth, whereas large inflows are less effective or even detrimental to productivity. This finding could also be picking up an aid/institutions interaction. ${ }^{29}$ To see how, begin by assuming that that institutional quality $Q$, is declining in aid inflows: $Q=\chi$ aid, $\chi<0 .{ }^{30}$ Next, suppose the 'true interaction' is

28 According to the analysis by Roodman (2004) the 'diminishing returns' specification is the most robust specification in the literature, next to the tropics interaction.

29 The standard interpretations of $\beta_{3}<0$ is a lack of 'absorptive capacity'. It is unclear, however, if this interpretation allow for a negative impact of aid when inflows reaches a certain threshold. Dalgaard (2008) suggest that $\beta_{3}<0$ also could proxy for the influence of donor policies.

${ }^{30}$ For example, aid agencies may recruit the best civil servants, or aid flows may lead to rampant corruption; see Knack (2001) for a discussion. 
with institutional quality: $Z=Q$. If $Z=Q$ we would expect to estimate $\beta_{3}>0$. That is, aid is more effective in places with a strong institutional infrastructure. But if aid matters for institutional quality we may simply substitute for $Q$ so as to obtain $Z=\chi$ aid. In this case the estimated coefficient on Zaid $=a^{a i d}{ }^{2}$ would be $\beta_{3} \chi<0$; the 'diminishing returns' result. Hence, the diminishing returns hypothesis could also, potentially, be consistent with an underlying aid/institutions interaction. Indeed, the model developed in section 3 lends itself readily to this idea. A resource inflow will initially spur growth if it impacts on productivity directly. However, at some point the incentive to engage in rent-seeking activities will off-set any conductive effect of the inflow on labour productivity. Further increases will lower average productivity.

Other contributions have more directly associated the impact of aid with institutions. Recent work of Collier and Dollar (2002) claim a larger impact of aid in countries with higher ratings according to the so-called CPIA index ('Country Policy and Institutional Assessment' index). ${ }^{31}$ Hence, if indeed the climate interaction picks up 'deep determinants' of institutions, Dalgaard et al. (2004) and the study by Collier and Dollar (2002) may be reaching a similar conclusion viz. the circumstances under which aid increases labour productivity. Another related finding is that of Svensson (1999), which suggests a larger impact of aid in countries with democratic institutions.

It is interesting to note the similarity to recent work on the impact of natural resources on growth. Indeed the empirical and theoretical work of Mehlum et al. (2006), as mentioned above, suggest that natural resource rents only spur growth in the presence of strong institutions; exactly what much of the evidence on the impact of aid on growth could be taken to imply also. Related findings are reported in Boschini et al. (2003) and Olsson (2007). Collier and Hoeffler (2005) find that natural resources rents may increase growth if associated with the right kind of political institutions.

Accordingly, we are left with an important question which we discuss in the next section: Do windfalls, of a sufficient magnitude

31 The robustness of this interaction cannot be assessed, however, since this data is still not in the public domain. Another drawback is that subjective indices like this one, based on reports by 'experts', are likely biased (see Mauro, 1995), and besides endogenous to GDP per capita (Dalgaard et al., 2004). 
perhaps, undermine institutional quality? If so then this would mean that aid and resource rents could lead to a form of institutional Dutch disease', whereby the economy ultimately ends up poorer than without the income flows. The existing literature on the effect of institutions on productivity suggests large impacts on labour productivity (Hall and Jones, 1999; Acemoglu et al., 2001). Hence, even if aid and resource flows are invested (in part), a positive effect on GDP per worker from capital accumulation is likely to be swamped by the harmful (side-) effects of a disintegrating institutional make-up. We discuss the literature on the impact from aid and natural resource rents on 'institutions' in the next section.

\section{Windfalls and Corruption}

A recent literature has started examining the impact of windfalls (i.e., aid and/or natural resource flows) on key aspects of 'institutional quality'. Roughly the literature partitions into three categories. i) Studies which examine the impact of windfalls on corruption; ii) studies which examine the impact of windfalls on broad proxies for institutional quality and finally iii) studies which examine the impact of windfalls on democracy. In this section, we will solely focus on the first type of studies which most clearly capture the rent-seeking aspects of our model.

Table 1 summarises the main findings as regards 'type 1 studies'. From a theoretical standpoint, the association between windfalls and rent seeking (as proxied by corruption) is a priori ambiguous, as illustrated by the analytical model from section 3 . On the one hand, windfalls may increase the incentive to engage in rent-seeking behaviour. On the other hand, to the extent that inflows are invested, in part at least, this may increase the opportunity cost of such activities. Accordingly, the association between resource inflows and rent seeking is an empirical issue to be resolved.

A common feature of the aid studies listed in Table 1 is that they use the same corruption measure, which derives from the International Country Risk Guide-database (ICRG). They also generally use the same measure of foreign aid; ODA flows. However, differences appear in terms of the measure for natural resource rents they employ. For example, whereas Svensson use the share of exports attributable to primary goods, Tavares uses a dummy 
Table 1: Previous Studies on Windfalls and Corruption

\begin{tabular}{|c|c|c|c|c|c|c|}
\hline Author & $\begin{array}{l}\text { Specific- } \\
\text { ation }\end{array}$ & $\begin{array}{l}\text { Esti- } \\
\text { mator }\end{array}$ & $\begin{array}{l}\text { Inter- } \\
\text { action }\end{array}$ & Aid & $\begin{array}{l}\text { Natural } \\
\text { resources }\end{array}$ & Impact \\
\hline $\begin{array}{l}\text { Alesina and } \\
\text { Weder (2002) }\end{array}$ & $\Delta C_{t}-\Delta C_{t-1}$ & OLS & No & Yes & No & $\div$ \\
\hline Knack (2001) & $\Delta \mathrm{C}_{\mathrm{t}}$ & IV & No & Yes & No & $\div$ \\
\hline Svensson (2000) & $C_{t}$ & IV & ELF & Yes & Yes & \pm \\
\hline Tavares (2003) & $\mathrm{C}_{\mathrm{t}}$ & IV & No & Yes & Yes & $\overline{+}$ (aid) + (n.r.) \\
\hline $\begin{array}{l}\text { Papyrakis and } \\
\text { Gerlagh (2007) }\end{array}$ & $\mathrm{C}_{\mathrm{t}}$ & OLS & No & No & Yes & + \\
\hline $\begin{array}{l}\text { Sala-i-Martin and } \\
\text { Subramanian } \\
(2003)\end{array}$ & $C_{t}$ & OLS & No & No & Yes & + \\
\hline $\begin{array}{l}\text { Leite and } \\
\text { Weidmann } \\
\text { (1999) }\end{array}$ & $C_{t}$ & OLS & No & No & Yes & + \\
\hline
\end{tabular}

Notes: + means positive and significant (i.e., less corruption), $\div$ means negative and significant, \pm means significant positive or negative, depending on interacting variable.

for oil producing countries. Moreover, even at the methodological level we see important differences. Not all papers treat foreign aid as endogenous (i.e., invoke instrumental variables (IV) methods) and the set of controls differs considerably. Even the way aid is allowed to enter the regression model (the specification itself) is subject to variation. Specifically, with regards to the latter Alesina and Weder estimate the acceleration (or de-acceleration) of changes in corruption in response to changes in aid, Svensson and Tavares implement a 'levels-levels' specification, whereas Knack can be viewed as adding some (ad hoc) dynamics to the empirical model of corruption while retaining comparability with the 'pure' level-specifications; changes in corruption is regressed on initial corruption and the level of aid.

Brushing these differences aside, and focusing on the influence from aid to begin with, we may observe that the literature reaches mixed conclusions. Knack (2001) and Alesina and Weder (2002) claim that aid increases corruption, whereas Tavares (2003) suggests 
the opposite. Svensson (2000) is somewhere 'in between', with aid increasing corruption only in sufficiently ethno-linguistically fractionalised (ELF) societies. In countries where ELF $<0.49$ aid lowers corruption. ${ }^{32}$ What can account for these differences in results?

One possibility of course, is that differences are due to the quality of invoked instruments for aid. As pointed out in section 2, the distribution of aid is not random. Indeed, it is a well-documented fact that low productivity countries tend to receive more aid, and that past colonial ties matter as well (e.g., Alesina and Dollar, 2000). That is not to say that corrupt regimes tend to receive more (or less) aid. Indeed, there seems to be some consensus among researchers working on aid allocation that disbursements are not affected by how corrupt the regime is (Alesina and Weder, 2002; Neumeyer, 2003); reverse causality is therefore unlikely to be a major problem. ${ }^{33}$ But there are reasons why aid would be endogenous nevertheless; measurement error and, in particular, omitted variable bias. Since aid is donated to poor performers there is always the risk that an omitted variable, which is positively correlated with GDP per capita, will end up biasing the OLS estimate of aid on corruption. Since rising GDP per capita tends to be associated with a lowering of corruption, this kind of bias would go in the direction of aid seemingly increasing corruption. However, since there is little theoretical guidance in choosing the specification when explaining corruption, the direction of the bias on the OLS estimate of aid on corruption is a priori unknown; the omitted variable could be positively correlated with aid donations while simultaneously being associated with more corruption. Clearly an IV-approach is called for. ${ }^{34}$

The three studies which invoke IV use only partially overlapping sets of instruments. In the study by Svensson the size of the population is the (only) excluded instrument which identifies the impact

32 The ELF index represents the probability of two randomly matched individuals belong to different ethnic groups.

33 As stressed in these, and other, contributions this is unlikely to be because aid agencies and multi-national organisations are indifferent to the presence of corruption. However, other goals tend to overwrite this concern; most notably the poverty alleviation agenda.

34 Alesina and Weder pursue a pure OLS strategy. Unfortunately the fit of their corruption specification is rather poor. With time dummies included the (adjusted) $R^{2}$ is a mere $6 \%$. Accordingly, omitted variable bias is almost guaranteed. 
of aid on corruption. Knack includes more instruments; initial GDP, initial population, a Franc zone dummy, a dummy for Central America and infant mortality in 1982. Finally the instrument for aid in Tavares' analysis is calculated as total aid disbursements by the Organisation for Economic Co-operation and Development (OECD), multiplied by a bilateral 'distance measure'-the measure can either be taken on a geographical dimension or a cultural one (e.g., depends on whether the donors and recipients have similar religion or not).

The weight one should attach to the findings of these papers depend on the answer to three key questions: i) Are the invoked instruments theoretically plausible? That is, should they explain aid?; ii) Are they plausibly excludable from the second stage? iii) Are they strong, in the sense of Staiger and Stock (1997)?

Generally the answer to the first question is 'yes'. All three studies have the aid allocation literature in mind when they pick their instruments. ${ }^{35}$

The answer to the second question, however, is generally ' $\mathrm{No}^{\prime}$. Two of the three studies use population as an excludable instrument. Recently, however, Knack and Azfar (2003) have shown that an empirically detected relation between the ICRG corruption index, and the size of population, is due to sample selection bias. Dysfunctional small countries are not covered to the same extent as large countries, by the survey underlying the ICRG data set. The reason is that the former group is not very interesting to multinational investors, who are the intended consumers of the data. Therefore, the size of population should be correlated with the corruption index for reasons that have nothing to do with foreign aid. The association between aid and corruption is therefore not solely due to the effect of size on aid allocation; the exclusion restriction is therefore likely to be invalid. Moreover, Tavares (2003) actually adds population to his set of controls, and finds it to be significant, casting further doubt on the identification strategy of Knack and Svensson.

It is worth noting that even if a different measure of corruption were chosen, the exclusion restriction would still be doubtful. For

${ }^{35}$ One exception is Knack's use of infant mortality rates in 1982. The association between mortality and aid allocation is in general ambiguous (e.g., Neumeyer, 2003). This is a little disquieting since Knack notes that the strongest predictor of aid in his set of instruments is in fact the infant mortality rate in 1982. 
example, it is well known that geographically large countries tend to rely less on foreign trade. If trade taxation is one area prone to corruption, then the size of the country could matter for the level of corruption by affecting the 'demand' for services rendered available by corrupt officials (Shleifer and Vishny, 1993).

Tavares study proceeds in a very creative way; the idea is that if donors and recipients are 'close', measured by cultural and geographic proximity, more aid should be given. This instrument could be viewed as part of the 'strategic interests' of donors.

Still, this approach is also open to critique. The fundamental question is whether culture and geographic distance to the OECD is likely to be unimportant to corruption (aside from its supposed indirect effect, via aid)? There are two reasons why one may not choose to answer in the affirmative. First, 'culture' is likely to have a direct effect on corruption, as evidence by Licht et al. (2004). Second, geographic distance has, by some, been suggested as an instrument for institutions more generally (Hall and Jones, 1999), which should affect the amount of corruption (or rent seeking) directly. For example, the analysis by Shleifer and Vishny (1993) suggests that the distorting effect of corruption, measured by its deadweight loss, would depend on whether bribes are collected by one or multiple agencies. If bribes are collected by one agency the deadweight loss is smaller, than if collected by multiple agencies. Hence, the organisation of government (e.g., in terms of the tax administration) might plausibly matter for corruption, and this in turn is likely affected by the colonial legacy. ${ }^{36}$ In sum, the problem can be put in terms of the model from section 3: If geography and culture matter for $\alpha$, it should matter for the level of rent seeking, for $F$ given. If so, then the identifying assumption of the paper is invalid, and the IV-results are suspect. Note that OID tests are not reported since Tavares (like Svensson) only uses one instrument at the time, it seems.

As for the third question there is no answer. None of the published studies provide a discussion of the issue, nor the relevant test statistics. This is a major problem, in that weak instruments render inference misleading. It is worth emphasizing that this

36 Some countries have historically adopted an organisational form labelled 'by type of tax', other an organisational form which could be labelled 'by function'. In the former case taxes are collected from, say, trade, VAT etc, in different departments-in the latter case only one department collects all taxes. 
critique can also be advanced towards the existing reduced form literature, discussed above.

The empirical relationship between natural resource rents and 'normal' forms of rent seeking and corruption have been analysed by a few studies. Leite and Weidmann (1999) use a 2SLS empirical model with economic growth as the ultimate dependent variable that is in part determined by corruption, which is in turn endogenous and explained by a number of factors in the first stage. Natural resources is one of the variables included to explain cross-country corruption levels (using the ICRG measure) and the article is one of the first attempts to disaggregate the natural resource category into fuels, ores, agriculture and food. It is shown that fuels and ores have a strong negative impact on corruption whereas agriculture and food appear to have the reverse effect. Furthermore, Leide and Weidmann show that GDP per capita levels, trade openness, and the strength of rule of law are negatively associated with levels of corruption. Ethnic fractionalisation has no clear impact, however, and neither has an Africa dummy. The included explanatory variables account for about $75 \%$ of the variation in crosscountry corruption levels.

In a robustness check section, Sala-i-Martin and Subramanian (2003, Table 6) throw in a corruption index (from Kaufmann et al., 2005) as a dependent variable in the first stage of a 2SLS. They try three proxies for natural resource abundance as explanatory variables and one of them-the share of exports of fuel, natural gas, and ores and minerals in total merchandise exports ('fuelandmineralshareEXP') - is negative and significant, as expected. ${ }^{37}$ Similarly, in their effort to sort out the transmission channels from natural resource abundance to growth, Papyrakis and Gerlagh (2004) show that their variable 'share of mineral production in GDP in 1971' ('SNP') alone explains only 7\% of the variation in the Transparency International Index of corruption for 1980-85. None of these two studies, however, are primarily designed to explain corruption.

A few theoretical articles provide more insightful accounts of the likely linkages between windfalls and rent-seeking behaviour. Tornell and Lane (1998) consider the effects of a temporary terms of trade boom, which the government is fully able to absorb.

37 The index is structured so that less corruption gives higher scores. 
The result of the windfall depends crucially on the government's control of the fiscal process. When governments (for various reasons) allow interest groups to compete over public funds (which in our model would imply a large $\gamma$ ), a windfall gain might induce a frenzy of rent-seeking activity that actually results in an appropriation of wealth that is larger than the windfall itself ('the voracity effect'). The outcome is a lower growth rate (due to lower investments) than before the terms of trade shock and also a current account deficit. Tornell and Lane (1998) argue that this scenario is able to explain the negative developments in Costa Rica, Cote d'Ivoir and Kenya after the 1975-79 coffee boom and Nigeria and Mexico after the 1979-82 oil boom.

Baland and Francois (2000) and Torvik (2002) both assume that productive workers have a choice between rent seeking and entrepreneurship. In Torvik (2002), public sector income and the flow of natural resource rents are both potentially appropriable and it follows naturally that an increase in natural resources will increase the number of rent seekers. In Baland and Francois (2000), rent seeking takes the form of attempts to obtain a rent flow resulting from holding an import quota. As in Torvik (2002), a resource boom in the sense of an increase in a primary factor of production increases the returns to rent seeking.

\section{A Reassessment of the Data}

As noted above the evidence on the association between windfalls and corruption is not strong; at least when it comes to aid and corruption. One possible reason, aside from the IV-strategies, is that the implemented regressions suffer from specification bias.

To motivate this claim begin by recalling that in section 3 we found the amount of resources used for rent-seeking purposes (which we proxy in the empirical portion below by the extent of corruption) to be given by:

$$
d^{*}=r^{*}=\frac{\alpha \gamma F}{A(1+\alpha)^{2}} .
$$

Now, as before, suppose the opportunity costs of rent-seeking activities do indeed depend on the inflow, $A(F)$. To fix ideas, 
consider the following functional form:

$$
A(F)=\left[\delta R^{(\varepsilon-1) / \varepsilon}+(1-\delta) F^{(\varepsilon-1) / \varepsilon}\right]^{\frac{\eta \varepsilon}{(\varepsilon-1)}},
$$

where $R$ represents other factors, beyond windfalls, which affect aggregate productivity (geography, world technology, outward orientation etc.). Without loss, we normalise $R$ to 1 in the remaining. Notice that the above specification allows for economies of scale if $\eta>1$. Moreover, it is straightforward to show that the specification for $A(F)$ fulfills the assumptions made in section 3 (i.e., $A^{\prime}(F)>0$, $A^{\prime \prime}(F)<0$ and $\left.A^{\prime}(0)=\infty\right)$ provided $\epsilon<1$ and $\eta>1$. Accordingly, these parameter choices are adopted for the illustration.

We may now proceed to work out the impact of $F$ on rent seeking. We find:

$$
\frac{\partial d}{\partial F}=\frac{\partial r}{\partial F}:\left\{\begin{array}{l}
\leq 0 \text { if } F \leq \tilde{F} \\
>0 \text { if } F>\tilde{F}
\end{array}\right.
$$

where

$$
\tilde{F} \equiv\left[\frac{(\eta-1)(1-\delta)}{\delta}\right]^{\frac{1}{1-\varepsilon}}>0 \text { iff } \eta>1 .
$$

Thus, modest levels of windfall gains (i.e., $F<\tilde{F}$ ) will reduce rent-seeking activities, whereas large inflows $(F>\tilde{F})$ have the opposite effect. The intuition for this result is simple. If the inflows are (in part) used for public goods which increase productivity (roads, law and order etc), or are associated with externalities and/or spillovers, then there are two countervailing forces on corruption, as measured by the size of $d$ (and/or $r$ ). On the one hand a larger inflow of funds will increase the amount of appropriable funds, which enhances the incentive to engage in rent-seeking activities. On the other hand, the inflow also increases over-all productivity thereby increasing the alternative costs associated with rent seeking (an 'opportunity cost effect'). What force dominates depends on the curvature of the $A\left({ }^{\prime}\right)$ function, and on the level of the inflows; the size of the inflow matters since $A^{\prime \prime}(F)<0$. In the case where $\eta>1, A$ is increased sufficiently, at low levels of $F$, to allow the 'opportunity cost effect' to dominate. However, if $\eta \leq 1$, the pure rent-seeking effect always dominates. 
The general point is that the impact of windfalls on rent seeking is a priori ambiguous. Moreover, regardless of the exact choice of functional form for $A(F)$, the marginal impact of $F$ on rent seeking will not necessarily be linear, as assumed in the existing literature on the topic. To examine whether non-linearities are present in the data we fit the following model:

$$
C=\beta_{0}+\beta_{1} F+\beta_{2} F^{2}+X_{i, t-\tau}^{\prime} \psi+\nu,
$$

where $C$ is the level of corruption, $F$ represents the windfall gainsaid and natural resource rents-and $X$ contains a set of other controls deemed potentially important to the level of corruption. Note that the theoretical model-in general-lends little guidance as to the expected sign of the two parameters $\left(\beta_{1}, \beta_{2}\right)$; they could be positive or negative depending on the exact shape of $A(F)$. As a result, the potential bias induced by omitting the squared term in the specification can only be assessed empirically.

Accordingly, the objective of our re-examination of the data will be to examine whether non-linear correlations are visible in the data, conditional on a plausible set of additional controls. Ideally the analysis would invoke appropriate instruments for, in particular, foreign aid (cf. the discussion in sections 2 and 5). Developing a plausible instrument for aid (and its square) is however beyond the scope of the present paper; it remains an important topic for future research.

Table 2 summarises the results from taking equation (10) to the data. Corruption, which derives from Kaufmann et al. (2005), is in Column I dependent on log GDP per capita and the 'Voice and Accountability index' (also from Kaufmann et al., 2005). The logic is that GDP per capita provides a partial control for the alternative costs of rent-seeking activities, whereas VOICE is a control for 'institutions'. ${ }^{38}$ As seen these two variables are highly correlated with corruption, accounting for $60 \%$ of the variation. The signs are as expected. If we add a full set of regional dummies (Column II) the $R^{2}$ rises to 0.7 .

38 The voice and accountability index is comprised of indicators that measure political rights, civil liberties, fairness and regularity of elections and the freedom of the press. Accordingly, this measure can be seen as a proxy for aspects of the institutional framework, which plausibly matter for the risk of detection in the context of corrupt behaviour, as well as affect the possibility of punishing a corrupt administration at the polls. 
Table 2: Windfalls and Corruption

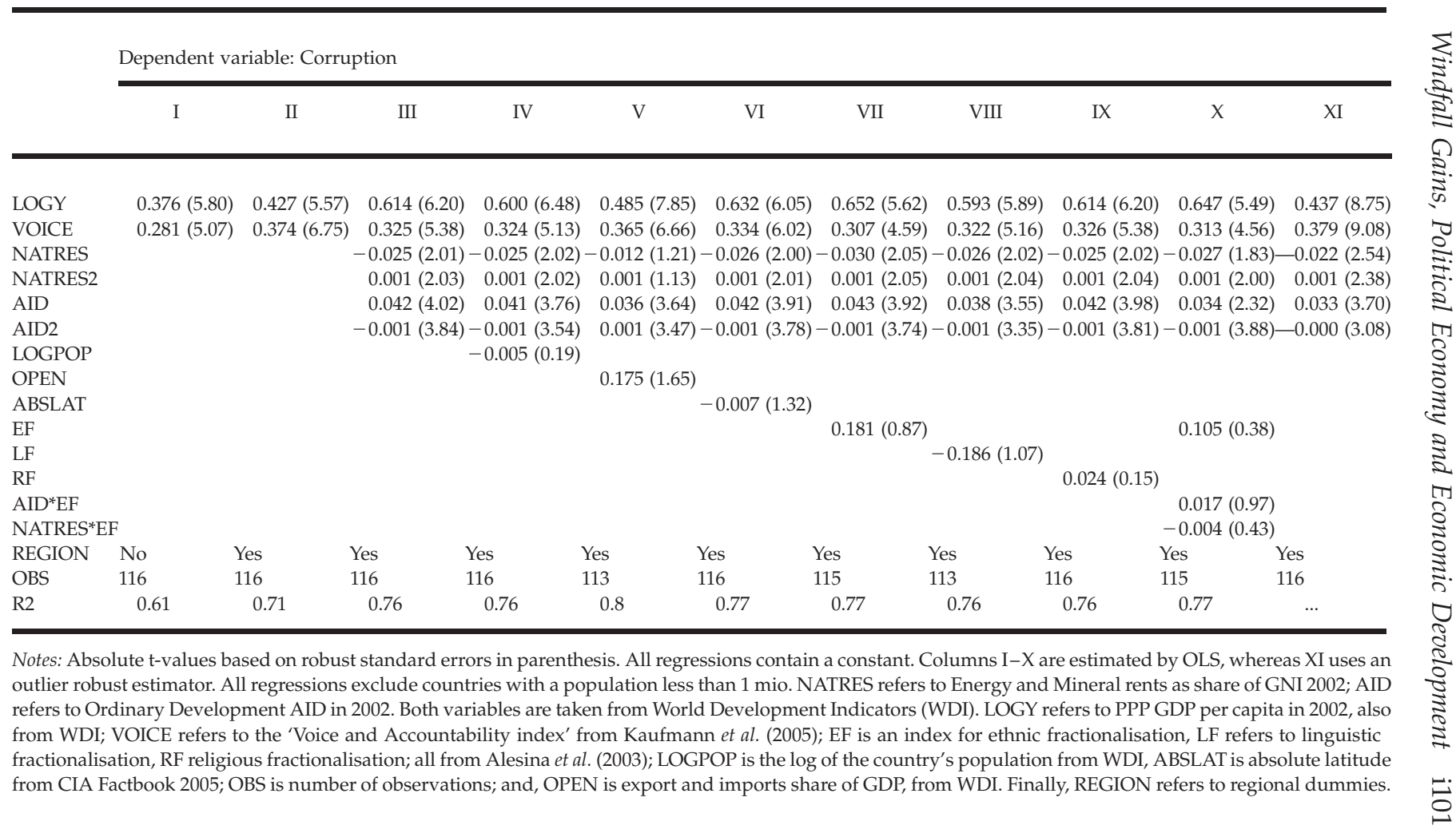

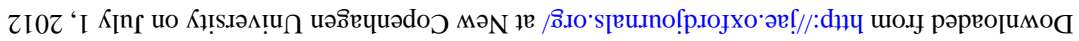


In Column III we add 'windfalls'; foreign aid and rents from energy and minerals as a share of GNI. The latter variable captures the type of resource rents that is generally believed to have the highest appropriablility $\gamma$ and includes revenue generated by oil, copper and gold, all of which are known to have spurred corruption.

As seen aid and resource rents seem to affect corruption in different ways. Foreign aid is associated with rising corruption only if given in sufficiently large amounts. In contrast, corruption tends to rise even with relatively modest levels of natural resource rents. Columns IV-X tests the robustness of the partial correlation between the non-linear windfall terms, and corruption. Notice in particular, that the interaction effects with ethnic fractionalisation is not significant (Column X). Finally, in Column XI we invoke an outlier robust estimator. The key findings do not seem to be particularly sensitive to influential observations; the four terms related to windfall gains survive this test as well.

These are merely partial correlations. Nevertheless it is interesting that these non-linear correlations are highly significant, and robust to the inclusion of a large set of controls. The association between natural resource rents and corruption conforms to expectations. The finding that aid is associated with less corrupt behaviour is perhaps more surprising. ${ }^{39}$ More generally, one may question the logic of why the two forms of windfalls should have a different impact.

In this respect, it is worth observing that an asymmetrical impact of aid and natural resource rents is theoretically plausible. As pointed out in section 2 , aid and resource flows differ in the important dimension that the former often is associated with conditions on how to spend the inflow. This is not meant to suggest that aid always is spent as intended by donors, nor should the statement be taken to imply that aid is not 'fungible'. However, conditions put forth by donors do make it more likely that the effect represented by $A^{\prime}(F)>0$ in the model is operating, and may be substantial. In contrast, as argued in section 2 , resource rents are not subject to similar conditions, which could motivate $A^{\prime}(F) \approx 0$. Against this background the difference in estimated impact may seem less puzzling.

That said, our OLS estimates do not necessarily reflect causal relationships. In particular, the association between aid and

39 Though Tavares (2003) report a similar finding, as mentioned in the last section. 
corruption could be ascribed to the fact that aid is endogenous. While reverse causality is unlikely to account for the result (cf. Alesina and Weder, 2002; Neumeyer, 2003), the OLS estimates may be misleading due to omitted variable bias.

Nevertheless, the results do indicate quite strongly that the impact from windfalls does not seem to be linear, as assumed in the existing literature. Moreover, this non-linearity is not readily explained away by omitted variable bias. As pointed out in section 4, a non-linear association between windfalls and (measures of) institutional quality may be the underlying reason for the reduced form non-linear impact of windfalls on prosperity, which have been detected in recent studies of aid and natural resource rents impact on GDP per capita growth. Hence, it appears there is more to be done on the important topic of windfalls impact on institutional quality in general, and corruption in particular.

\section{Concluding Remarks}

In this paper, we have critically reviewed the literature on both the direct impact of windfall gains on economic growth and the indirect influence, working through institutional quality. We have also provided some additional empirical evidence on the windfall/institutional quality interface, where the latter is measured by corruption. More specifically, we have reached the following broad conclusions.

The observed impact from windfalls (aid, resource rents) on labour productivity can arguably be attributed to the interaction with institutions, at least in part. Both more recent as well as historical evidence seem to support the claim that highly appropriable natural resources, like oil and precious minerals, have a negative impact on measures of institutional quality like the rule of law-index or corruption. The association between the latter and windfalls in the shape of foreign aid is harder to pin down. The difficulties in the latter respect is likely related to the fact that aid involves both income flows as well as terms of conditionality, the respective impact from which is hard to disentangle. In addition, the allocation of aid is, in contrast with natural resource wealth, highly systematic and related to economic outcomes such as GDP per capita. Finally, as we have documented above, the existing literature may have overlooked what appears to be strong non-linear correlation between windfalls and our measure of institutional 
quality: corruption. We believe general progress on the topic of how windfalls and growth are connected requires a clearer understanding of the mechanisms through which windfalls affects long run labour productivity; only few studies have tried to come to grips with this challenge so far. Accordingly, more work in 'channelling' the impact of windfalls to labour productivity is clearly needed.

Edging closer to this goal, e.g., by establishing a link between windfalls and institutional quality, requires progress in the area of identification. Better instruments for aid, in particular, needs to be developed. This, in turn, will likely require more work on topic of aid allocation. Such work may unravel determinants of aid flows which are plausible candidates as instruments. Currently, the best suggestions are variables which reflect colonial past, and the size (population, area) of the recipient nations. However, both categories of variables are possible direct determinants of institutional quality themselves, which makes the crucial exclusion restriction doubtful. As a result, theoretical work on why rich countries donate aid, and allocate it the way they do, seems called for. Perhaps time-varying factors, such as demographic composition of OECD populations, which might affect the willingness to forego domestic public consumption, could be shown to affect aid flows.

Regarding research on the other type of windfall-natural resource rents-progress on measurement would be welcome. At this stage the literature is plagued by the difficulty of correctly assessing natural resource wealth; should one use levels of production, share of exports to GDP or GNI, continue bundling minerals together with food? Should measures of reserves rather than current extraction be used? If natural resource rents are volatile, is it really reserves which matter, or are 'resource booms' the culprit? Future research would also benefit from case studies that are structured around the regularities found at the macro level. The creation of institutions for handling diamond and oil rents is undoubtedly an area of particularly high policy relevance.

\section{Acknowledgements}

We appreciate useful comments from our discussant Mwangi Kimenyi as well as from Arne Bigsten, Anke Hoeffler and the participants at the AERC Conference in Nairobi. 
Windfall Gains, Political Economy and Economic Development i105

\section{Funding}

Olsson gratefully acknowledges financing from the African Economic Research Consortium, Vetenskapsrådet, and SIDA.

\section{References}

Acemoglu, D., S. Johnson and J.A. Robinson (2001) 'The Colonial Origins of Comparative Development: An Empirical Investigation', American Economic Review, 91 (5): 1369-401.

Acemoglu, D., S. Johnson and J.A. Robinson (2005) 'Institutions as the Fundamental Cause of Long-Run Growth', in P. Aghion and S. Durlauf (eds), Handbook of Economic Growth. Volume 1A, Amsterdam: Elsevier.

Acemoglu, D., J. Robinson and T. Verdier (2004) 'Kleptocracy and Divide-and-Rule: A Model of Personal Rule', Journal of the European Economic Association, 2 (2-3): 162-92.

Aidt, T. (2003) 'Economic Analysis of Corruption: A Survey', Economic Journal, 113: 632-52.

Alesina, A. and D. Dollar (2000) ‘Who gives foreign aid to Who and Why?', Journal of Economic Growth, 5: 33-63.

Alesina, A., A. Devleeschauwer, W. Easterly, S. Kurlat and R. Wacziarg (2003) 'Fractionalization', Journal of Economic Growth, 8: 155-94.

Alesina, A. and B. Weder (2002) 'Do Corrupt Governments Receive Less Foreign Aid?', American Economic Review, 92: 1126-37.

Azarnert, L.V. (2004) 'Foreign Aid, Fertility and Population Growth: Evidence from Africa', Mimeo, Tel-Aviv University.

Baland, J-M. and P. Francois (2000) 'Rent Seeking and Resource Booms', Journal of Development Economics, 61 (1): 527-42.

Boschini, A., J. Pettersson and J. Roine (2003) 'Resource Curse or Not: A Question of Appropriability', Mimeo, Stockholm University.

Buchanan, J.M. (1975) 'The Samaritan's Dilemma', in E. Phelps (ed), Altruism, Morality and Economic Theory, New York: Russel Sage Foundation, pp. 71-85.

Burnside, Craig and David Dollar (2000) 'Aid, Policies, and Growth', American Economic Review, 90 (4): 847-68. 
Chenery, H.B. and A.M. Strout (1966). 'Foreign Assistance and Economic Development', American Economic Review, 56: 679-733.

Clemens, M.A., S. Radelet and R. Bhavnani (2004) 'Counting Chickens when They Hatch: The Short Term Effect of Aid on Growth', Working Paper No. 44, Center for Global Development.

Coate, S., 1995. 'Altruism, the Samaritan's Dilemma, and Government Transfer Policy', American Economic Review, 85: $46-57$.

Collier, P. and D. Dollar (2002) 'Aid allocation and poverty reduction', European Economic Review, 45: 1470-500.

Collier, P. and A. Hoeffler (2005) Democracy and Resource Rents, GPRG-WP-016.

Corden, M. and J.P. Neary (1982) 'Booming Sector and Dutch Disease Economics: A Survey', Economic Journal, 92: 826-44.

Dalgaard, C-J (2008) 'Donor Policy Rules and Aid Effectiveness', Journal of Economic Dynamics and Control.

Dalgaard, C-J. and Henrik Hansen (2001) 'On Aid, Growth and Good Policies', Journal of Development Studies, 37 (6): 17-41.

Dalgaard, C-J., H. Hansen and F. Tarp (2004) 'On the Empirics of Foreign Aid and Growth', Economic Journal, 114 (496): 191-216.

Diamond, J. (1997) Guns, Germs, and Steel: The Fates of Human Societies, New York: Norton.

Easterly, W., R. Levine and D. Roodman (2004) 'New Data, New Doubts: A Comment on Burnside and Dollar's Àid, Policies, and Growth', American Economic Review, 94: 774-80.

Galor, O. (2006). 'From Stagnation to Growth: Unified Growth Theory', in P. Aghion and S. Durlauf (eds), Handbook of Economic Growth, Volume IA, Amsterdam, North Holland.

Galor, O. and D. Weil (2000) 'Population, Technology, and Growth: From Malthusian Stagnation to the Demographic Transition and Beyond'. American Economic Review, 90: 806-28.

Grossman, H.I. (1991) 'A General Equilibrium Model of Insurrections'. American Economic Review, 81(4): 912-21.

Grossman, H.I. and M. Kim (1995) 'Swords or Plowshares? A Theory of the Security of Claims to Property', Journal of Political Economy, 103 (6): 1275-88. 
Gylfason, T. (2001) 'Natural Resources, Education and Economic Development', European Economic Review, 45: 847-59.

Hall, Robert E. and C.I. Jones (1999) 'Why Do Some Countries Produce So Much More Output per Worker Than Others?', Quarterly Journal of Economics, 114: 83-116.

Hansen, H. and F. Tarp (2000) 'Aid Effectiveness Disputed', Journal of International Development, 12: 375-98.

Hansen, H. and F. Tarp (2001) 'Aid and Growth Regressions', Journal of Development Economics, 64: 547-70.

Hodler, R. (2006). 'Rent Seeking and Aid Effectiveness', Tax and Public Finance, 14: 525-41.

Kaufmann, D., A. Kraay and M. Mastruzzi (2005) 'Governance Matters IV: Governance Indicators for 1996-2004', World Bank Policy Research Working Paper 3630.

Knack, S. (2001) 'Aid Dependence and the Quality of Governance: A Cross-Country Empirical Analysis', Southern Economic Journal. 68 (2): 310-29.

Knack, S. and O. Azfar (2003) 'Trade Intensity, Country Size and Corruption', Economics of Governance, 4: 1-18.

Knack, S. and P. Keefer (1995) 'Institutions and Economic Performance: Cross-Country Tests Using Alternative Institutional Measures', Economics and Politics, 7 (3): 207-225.

Leite, C. and J. Weidmann (1999) 'Does Mother Nature Corrupt? Natural Resources, Corruption and Economic Growth', IMF Working Papers 99/85.

Licht, A., C. Goldschmidt and S. Schwartz (2004) 'Culture Rules: The Foundations of the Rule of Law and Other Norms of Government', Mimeo, University of California at Berkely.

Manzano, O. and R. Rigobon (2001) 'Resource Curse or Debt Overhang?', NBER Working Paper 8390, NBER.

Mauro, P. (1995) 'Corruption and Growth', Quarterly Journal of Economics, 110: 681-712.

Matsuyama, K. (1992) 'Agricultural Productivity, Comparative Advantage, and Economic Growth', Journal of Economic Theory, 58: $317-34$. 
Mehlum, H., K. Moene and R. Torvik (2006) 'Institutions and the Resource Curse', Economic Journal, 116 (508): 1-20.

Neary, H. (1997) 'A Comparison of Rent-Seeking Models and Economic Models of Conflict', Public Choice, 93: 373-88.

Neumeyer, E. (2003) 'The Determinants of Aid Allocation by Regional Multilateral Development Banks and United Nations Agencies', International Studies Quarterly, 47: 101-22.

North, D. (1990) Institutions, Institutional Change and Economic Performance, Cambridge: Cambridge University Press.

Olsson, O. (2006) 'Diamonds Are A Rebel's Best Friend' The World Economy, 29 (8): 1133-50.

Olsson, O. (2007) 'Conflict Diamonds', Journal of Development Economics, 82 (2): 267-86.

Olsson, O. and H. Congdon Fors (2004) 'Congo: The Prize of Predation', Journal of Peace Research 41 (3): 321-336.

Papyrakis, E. and R. Gerlagh (2004) 'The Resource Curse Hypothesis and Its Transmission Channels', Journal of Comparative Economics 32 (1): 181-93.

Papyrakis, E. and R. Gerlagh (2007) 'Resource Adundance and Economic Growth in the US', European Economic Review 51 (4): 1011-39.

Rajan, R. and A. Subramanian (2005) 'Aid and Growth: What Does the Cross-Country Evidence Really Show?', NBER Working Paper 11513, NBER.

Reher, D. (2004) 'The Demographic Transition Revisited as a Global Process', Population, Space and Place, 10: 19-41.

Roodman, D. (2004) Anachy of Numbers: Aid, Development and Cross-country Empirics, Washington DC: Center for Global Development.

Sachs, J. and A.M. Warner (1997) 'Natural Resource Abundance and Economic Growth', Mimeo, Harvard University.

Sachs, J. and A.M. Warner (2001) 'The Curse of Natural Resources', European Economic Review, 45: 827-38.

Sala-i-Martin, X. and A. Subramanian (2003) 'Addressing the Natural Resource Curse: An Illustration from Nigeria,' NBER Working Paper No. 9804, NBER. 
Shleifer, A. and R.W. Vishny (1993) 'Corruption', Quarterly Journal of Economics, 108: 599-617.

Sokoloff, Kenneth L. and Stanley L. Engerman (2000) 'Institutions, Factor Endowments, and Paths of Development in the New World', Journal of Economic Perspectives, 14: 217-32.

Staiger, D. and J. Stock (1997) 'Instrumental Variables Regression with Weak Instruments', Econometrica, 65 (3): 557-86.

Stijns, J-P. (2001) 'Natural Resource Abundance and Economic Growth Revisited', Mimeo, University of California, Berkeley.

Svensson, J. (1999) 'Aid, Growth and Democracy', Economics and Politics, 11: 275-97.

Svensson, J. (2000) 'Foreign Aid and Rent Seeking', Journal of International Economics, 51: 437-461.

Tavares, J. (2003) 'Does foreign aid corrupt?', Economics Letters, 79: 99-106.

Tornell, A. and P.L. Lane (1998) 'Are Windfalls a Curse? A Non-representative Agent Model of the Current Account', Journal of International Economics, 44 (1): 83-112.

Torvik, R. (2001) 'Learning-by-Doing and Dutch Disease'. European Economic Review, 45: 285-306.

Torvik, R. (2002) 'Natural Resources, Rent Seeking and Welfare' Journal of Development Economics 67: 455-70.

Tullock, G. (1974) The Social Dilemma: The Economics of War and Revolution, Fairfax, VA: Center for the Study of Public Choice. 